\title{
Hedonic shift learning based on calories
}

\author{
RONALD MEHIEL and ROBERT C. BOLLES \\ University of Washington, Seattle, Washington
}

\begin{abstract}
Rats were conditioned to prefer a flavor that was paired with sucrose. When tested with flavored water and flavored chows, the rats preferred the calorie-paired flavor in both the familiar solution form and the new chow form. It is suggested that the hedonic value of a flavor enjoys a positive shift by association with calories, and that the shift is mediated centrally by a peripheral cholecystokinin reflex.
\end{abstract}

There is growing interest in conditioned flavor preferences. Curiously, the evidence for the conditioning of flavor preferences based upon calories was rather scarce until recently (Bolles, Hayward, \& Crandall, 1981; Booth, 1972, 1982; Capaldi, Campbell, Sheffer, \& Bradford, 1987; Fedorchak \& Bolles, 1987; Hayward, 1983; Mehiel \& Bolles, 1984; Simbayi, Boakes, \& Burton, 1985, 1986). Such conditioning has now been found even when the calories are from a source with negative unconditioned hedonic value, such as ethanol (Crawford \& Baker, 1982; Deems, Oetting, Sherman, \& Garcia, 1986; Deutsch \& Walton, 1977; Fedorchak \& Bolles, 1988; Mehiel \& Bolles, 1984).

Such learned preferences based on calories suggest the existence of some kind of calorie recognition mechanism. Perhaps calorie receptors, or rate of stomach emptying, or stomach distension, or some other as yet unknown physiological mechanism has evolved to monitor calories. It is appealing to look for these kinds of mechanisms, for they could serve as a basis for weight regulation. However, another way to study the learning of flavor preferences due to their pairing with caloric substances is to focus on the animal's hedonic response. Zellner, Berridge, Grill, and Ternes (1985) reported that rats' facial responses to the bitter taste of morphine in the taste reactivity test change from "dislike" to "like" after forced drinking of morphine over a period of several days. Similarly, when sucrose is directly infused into the oral cavity of rats while they are tasting normally avoided hydrochloric acid or quinine, the taste reactivity test reveals a shift from negative to positive facial responses (Breslin, Davidson, \& Grill, 1987). Evidently, there is a hedonic shift.

There are obviously many features of a food that might serve as the effective conditioned stimulus in hedonic shift learning. The rat might come to like the hardness, chewiness, texture, or temperature of a food in addition to, or instead of, its taste per se. However, recent work on potentiation (Rusiniak, Hankins, Garcia, \& Brett, 1979) suggests that taste has a privileged place among the different sensory properties. Taste is first and foremost of the

Address correspondence to Ronald Mehiel, Department of Psychology, University of Washington, Seattle, WA 98195. sensory dimensions to be conditioned negatively. Moreover, when other dimensions are conditioned, it is because those dimensions are "potentiated" by taste. In the present study, we associated a distinctive taste with a sugar solution, and then tested for the preference of that taste when it was presented in a quite different format, in rat chow.

\section{METHOD}

\section{Subjects}

The animals were 8 male Long-Evans rats with a mean weight of $376 \mathrm{~g}$. They were housed individually in hanging metal cages in a vivarium where the lights went on at $0800 \mathrm{~h}$ and off at $2000 \mathrm{~h}$. Except as noted below, they were fed $12 \mathrm{~g}$ of Wayne Lab Blox daily at $0830 \mathrm{~h}$. Water was freely available except during conditioning and testing.

\section{Flavored Solutions and Chows}

Conditioning and test solutions were flavored with cherry or grape unsweetened Kool Aid (General Foods). One 4-g package was dissolved in $1,600 \mathrm{ml}$ of tap water. The flavored sucrose solution was prepared by adding either cherry or grape water to $60 \mathrm{~g}$ of sucrose (C\&H brand table sugar) to make $400 \mathrm{ml}$. This yielded a $15 \% \mathrm{w} / \mathrm{v}$ solution. The saccharin (sodium saccharin, Sigma Chemical Co.) solutions were prepared in the same manner, but the concentration was .10\% w/v. Flavored test chows were prepared by adding cherry- or grape-flavored water to powdered chow, $50 \% \mathrm{w} / \mathrm{v}$. The concentration of Kool Aid flavors was doubled to overcome the inherent taste of the chow.

Conditioning solutions were made fresh daily $1 \mathrm{~h}$ before presentation to the rats and allowed to stand at room temperature during that hour. Solutions were delivered to the rats via 250 -ml glass bottles with rubber stoppers and metal spouts. The flavored mash was presented in wide-mouth 50-ml glass jars. Solutions were attached by springs to the center of the fronts of the cages, and the jars of mash were placed on the floors inside the cages.

\section{Procedure}

Upon arrival in the lab, the rats were weighed and placed in their home cages. For the next 7 days they had water ad lib and were given $12 \mathrm{~g}$ of chow at $0830 \mathrm{~h}$. On Day 1 of conditioning, water was replaced by grape-flavored saccharin for half the rats and cherry-flavored saccharin for the other half. On Day 2 at $0800 \mathrm{~h}$ the saccharin bottles were removed, the daily $12-\mathrm{g}$ food ration was presented, and at $0830 \mathrm{~h}$ each rat was presented with the opposite flavored sugar solution. The amount of sugar solution made available to a rat was equal to what it had consumed of the saccharin solution the day before. This yoking procedure was used to keep the amount of exposure to each flavor constant for each rat. Conditioning followed this alternating procedure for 8 days, with every odd day being a replication of the first, and every even day a replication of the second. Thus each rat had equal experience with saccharin and sugar solutions, and equal experience with cherry and 
grape flavors. Following conditioning, all rats had the usual $12 \mathrm{~g}$ of chow and water ad lib for $24 \mathrm{~h}$. The next day at $0800 \mathrm{~h}$, water was removed and each rat was presented with the two jars of flavored mash for $30 \mathrm{~min}$. Spillage was collected, and the amount consumed of each flavor was calculated. The rats were then placed on ad-lib chow and water for 3 days. This was followed by a 30 -min two-bottle preference test between cherry- and grape-flavored water. The rats were then fed $12 \mathrm{~g}$ of chow and the unflavored water was returned; the following day at $0800 \mathrm{~h}$, the second 30 -min two bottle preference test between cherry and grape water ensued.

\section{RESULTS AND DISCUSSION}

The intake data from the chow test were subjected to a repeated measures analysis of variance; the data from the two-bottle flavored water tests were combined and tested by a repeated measures analysis of variance for factorial designs (Edwards, 1985). Mean intakes during conditioning and tests, collapsed across flavors, are shown in Figure 1. During the 30-min chow test, the flavor paired with calories in conditioning was preferred $[F(1,7)$ $=6.84, p<.05]$. The results of the two-bottle flavored water tests were essentially a replication of the chow test: the preference was for the flavor paired with calories $[F(1,7)=11.95, p<.02]$.

The rats learned to prefer the flavor paired with calories in conditioning, and the preference manifested itself in both tests regardless of the test conditions. Because the details of the consummatory responses themselves were different in the two tests, lapping versus chewing, it seems clear that response topography was not being conditioned.

One might suppose that the taste of the calorie-paired flavor results in a conditioned expectancy of caloric benefit, or of positive postingestional effects. Very simply, perhaps the rat learns that one flavor means food and that the other does not. There are a variety of conditioned

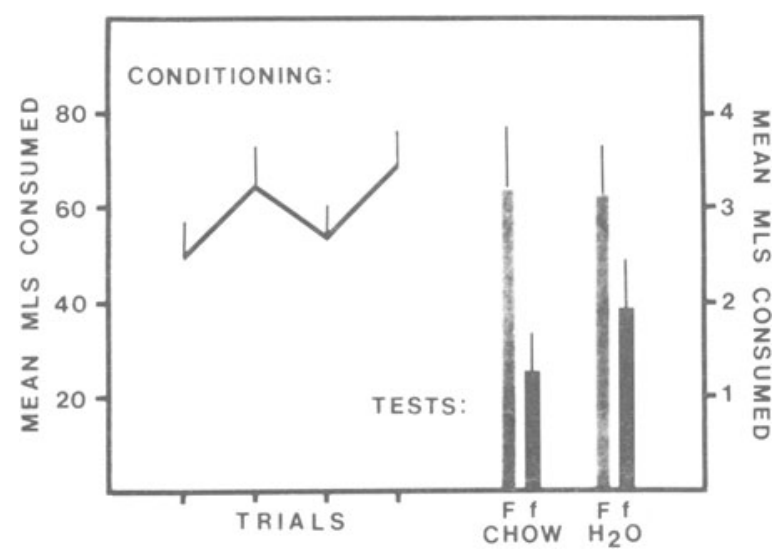

Figure 1. Mean intakes during conditioning and testing. During conditioning, sucrose and saccharin solutions were yoked, so the lines fall on top of each other. Intake of the sucrose-paired flavor and intake of the saccharin-paired flavor during the tests are represented by the light bars and the dark bars, respectively. Vertical lines are standard errors of the means. expectancy explanations that could be used to account for preference learning without invoking any hedonic or incentive motivation concepts; however, we would like to disregard all of them. Although terms such as caloric expectancy are useful in explaining data, they make no contact with the rat. What does seem reasonable is that the rat, because of its conditioning history, comes to like the flavor that has predicted calories. Explanations based on conditioned expectancies cannot account for the results of the chow test in the present experiment. The rats have no paucity of experience with chow. They eat it every day. If our conditioning procedure results in an expectancy about the consequences of ingestion, then it would already have such an expectancy about chow. During the test both jars contained chow; hence, flavor cues would be redundant.

If we view the conditioning process as resulting in a positive hedonic shift for the calorie-paired flavor, then it all becomes clear. The rat eats more of the flavored chow in the test because the flavor has hedonic value; the rat likes it.

We propose that cholecystokinin (CCK) mediates hedonic shift learning. Waldbillig and O'Callaghan (1980) argued that CCK, the neuropeptide that controls (among other things) stomach emptying (Brener, Hendrix, \& McHugh, 1983; Moran \& McHugh, 1982) primarily via receptors located on the pyloric sphincter and the distal gastric antrum (McHugh \& Moran, 1986), may be the physiological stimulus that controls alliesthesia (Cabanac, 1971). Cabanac coined the term alliesthesia to account for the reduction in pleasantness ratings given to sucrose solutions following their ingestion.

Information about CCK actions at the duodenum may be integrated at higher levels to reduce incentive motivation and in this way bring about the end of a meal. Cholycystokinin receptors migrate distally via the vagus (Smith, Jerome, Cushin, Eterno, \& Simansky, 1981) toward the gut. These receptors seem to serve a sensory function. This sensory information is transferred via the vagus to the nucleus tractus solitaris (NTS), then to the paraventricular nucleus (PVN). Crawley, Kiss, and Mezey (1984) made sections all along this sensory route to the central nervous system (CNS) and disrupted the behavioral satiety effects of CCK at every step. The highest concentrations of CCK receptors in the CNS are in the cerebral cortex (Baile, McLaughlin, \& Della-Fera, 1986). Additionally, the PVN, dorsomedial nucleus, and ventromedial nucleus of the hypothalamus are high in CCK receptors (Baile et al., 1986; Loren, Alumets, Hakanson, \& Sundler, 1979). The hypothalamus has long been implicated in motivational functions (Kupfermann, 1981; Olds \& Milner, 1954). Lesions of the dorsomedial nucleus of the hypothalamus block the suppression effects on meal size evident when CCK is administered in the peritoneal cavity (Bellinger \& Bernardis, 1984), and thus may be acting directly on hypothalamic motivational controls. In 
sheep, the suppressive effects of CCK are related to the amount of deprivation the animals are under. In other words, the more motivated the sheep, the more CCK is required to get equal suppression of intake (Baile et al., 1986). Additionally, CCK antiserum delivered into the lateral ventricles increases feeding in sheep (Della-Fera \& Baile, 1984). Thus, it appears that CCK interacts with motivation.

Since CCK appears to interact with central motivational controls, perhaps a flavor acquires a positive hedonic value during conditioning because its ingestional consequences produce a duodenal CCK response. Then, because of its acquired hedonic value, that flavor is preferred on future encounters. McHugh and Moran (1986), for example, convincingly showed that loading the stomach with sugar solution triggers the CCK system. If, after conditioning, the flavor comes to serve as a label for the caloric solution, then it could elicit a conditioned CCK response. More research is needed to ascertain the conditionability of the CCK response. There is some evidence that learning does occur. McHugh and Moran (1981) reported that a xylose load resulted in the typical CCK modulation of gastric emptying in their monkey, but only on the first trial. On succeeding days, xylose was emptied at the same rate as saline.

In summary, we propose a model of learned flavor preferences that are modulated by incentive motivation. The physiological stimulus that produces shifts in hedonic value, or incentive, is the integration of the reflexive CCK response in the periphery. We hypothesize that the actions of this reflex are monitored centrally and integrated at the hypothalamus along with sensory information about the taste of the flavor, and that together they determine the hedonic value of the flavor. Probably any nutritive substance that brings about this reflex will get this motivational system going. Although the model may seem counterintuitive in that CCK is putatively a satiety hormone, we propose that CCK has both short- and long-term effects. The short-term effects are well-documented and serve to activate the motivational state generally described as satiety. The long-term effects are not well-documented, although perhaps the present experiment makes a start.

How can CCK both reduce hedonic value within a meal and increase hedonic value across meals? Booth (1972) argued that highly satiating foods are preferred over less satiating foods. We concur with that notion. We believe that through a conditioned reflexive release of CCK in the periphery and the activation of directly related CNS structures, an animal learns to prefer flavors paired with calorie sources. We envision a system in which, through learning, anything that predicts the CCK response will have high incentive value initially. This accounts for the initiation of the meal. As the CCK response occurs due to the food's actually arriving in the duodenum, CCK receptors on the vagus are occupied, and this action leads to a within-meal decrease in motivational value. As in- centive value for the flavor decreases, the meal is terminated.

A number of predictions can be made from this model. Waldbillig and Bartness (1982) reported that the suppressive effects of CCK were directly related to the caloric density of a sucrose solution. If our model were correct, then learned preferences should also covary directly with both caloric density and the magnitude of the CCK response. There is a bit of evidence to support this notion. Mehiel and Bolles (1984) reported that when two solutions did not differ in caloric value, there was no learned preference for a flavor paired with one over the other. This was true even when either solution would condition a preference when contrasted with a noncaloric solution. Additionally, when flavors are paired with two chows, one of which is more calorically dense than the other, rats prefer the dense-paired flavor in a test (Bolles et al., 1981). However, the proper experiments have not yet been done to examine critically the relationship between preference, caloric density, and the CCK response. The model also accounts for the decrement of preference found when rats are tested sated (Fedorchak \& Bolles, 1987), as the state of satiation should reduce incentive value of a target flavor.

Many years ago Young (1948) said "rats take what they need to maintain homeostasis ... and take what they like regardless of need"' (p. 319). If the CCK mechanism that precedes caloric repletion causes hedonic shift learning, then all the rat needs to do is eat what it likes. The calories will take care of themselves.

\section{REFERENCES}

Baile, C. A., Mclaughlin, C. L., \& Della-Fera, M. A. (1986). Role of cholecystokinin and opioid peptides in control of food intake. Physiological Reviews, 66, 172-234.

Bellinger, L. L., \& BerNaRdis, L. L. (1984). Suppression of feeding by cholecystokinin but not bombesin is attenuated in dorsomedial hypothalamic nuclei lesioned rats. Peptides, 5, 547-552.

Bolles, R. C., Hayward, L., \& Crandall, C. (1981). Conditioned taste preferences based on caloric density. Journal of Experimental Psychology: Animal Behavior Processes, 7, 59-69.

Booth, D. A. (1972). Conditioned satiety in the rat. Journal of Comparative \& Physiological Psychology, 81, 457-471.

Booth, D. A. (1982). Normal control of omnivore intake by taste and smell. In J. Steiner \& J. Ganchrow (Eds.), The determination of behavior by chemical stimuli. ECRO Symposium (pp. 233-243). London: Information Retrieval.

Brener, W., Hendrix, T. R., \& McHugh, P. R. (1983). Regulation of the gastric emptying of glucose. Gastroenterology, 65, 76-82.

Breslin, P., Davidson, T., \& Grill, H. (1987, April). Conditioned changes in rat taste reactivity to normally avoided taste stimuli as a result of pairings with a normally preferred taste stimulus. Paper presented at the 58th Annual Meeting of the Eastern Psychological Association, Arlington, VA.

Cabanac, M. (1971). Physiological role of pleasure. Science, 173, 1103-1107.

Capaldi, E., Campbell, D. H., Sheffer, J. D., \& Bradford, J. P. (1987). Conditioned flavor preferences based on delayed caloric consequences. Journal of Experimental Psychology: Animal Behavior Processes, 13, 150-155. 
Crawford, D., \& BAKer, T. B. (1982). Alcohol dependence and taste mediated learning in the rat. Pharmacology, Biochemistry \& Behavior, 16, 253-261.

Crawley, J. N., Kiss, J. Z., \& Mezey, E. (1984). Bilateral midbrain transection blocks the behavioral effects of cholecystokinin on feeding and exploration in rats. Brain Research, 322, 316-321.

Deems, D. A., Oetting, R. L., Sherman, J. E., \& Garcia, J. (1986). Hungry, but not thirsty, rats prefer flavors paired with ethanol. Physiology \& Behavior, 36, 141-144.

Della-Fera, M. A., \& Baile, C. A. (1984). Control of feed intake in sheep. Journal of Animal Science, 59, 1362-1368.

Deutsch, J. A., \& Walton, N. Y. (1977). A rat alcoholism model in a free choice situation. Behavioral Biology, 19, 349-360.

EDWARDS, A. L. (1985). Experimental design in psychological research (5th ed.). New York: Harper \& Row.

Fedorchak, P. M., \& Bolles, R. C. (1987). Hunger enhances the expression of calorie- but not taste-mediated conditioned flavor preferences. Journal of Experimental Psychology: Animal Behavior Processes, 13, 73-79.

FedorchaK, P. M., \& Bolles, R. C. (1988). Nutritive expectancies mediate cholecystokinin's suppression-of-intake effect. Behavioral Neuroscience, 102, 451-455.

HAYWARD, L. (1983). The role of oral and postingestional cues in the conditioning of taste preferences based on differing caloric density and caloric outcome in weanling and mature rats. Animal Learning \& Behavior, 11, 325-331.

KupfermanN, I. (1981). Hypothalamus and limbic system: II. Motivation. In E. Kandel \& J. H. Schwartz (Eds.), Principles of neural science. New York: Elsevier/North-Holland.

Loren, I., Alumets, J., Hakanson, R., \& Sundler, F. (1979). Distribution of gastrin and CCK-like peptides in rat brain: An immunocytochemical study. Histochemistry, 59, 249-257.

McHugh, P. R., Moran, T. H. (1981). Distinctions among three sugars in their effects on gastric emptying and satiety. American Journal of Physiology, 241 (Regulatory Integrative Comparative Physiology, 10), R25-R30.
McHugh, P. R., \& Moran, T. H. (1986). The stomach, cholecystokinin, and satiety. Federation Proceedings, 45, 1384-1390.

MehiEL, R., \& Bolles, R. C. (1984). Learned flavor preferences based on caloric outcome. Animal Learning \& Behavior, 12, 421-427.

Moran, T. H., \& MCHugh, P. R. (1982). Cholecystokinin suppresses food intake by inhibiting gastric emptying. American Journal of Physiology, 242 (Regulatory Integrative Comp. Physiol. 11), R491-R497.

OldS, J., \& Milner, P. (1954). Positive reinforcement produced by electrical stimulation of septal area and other regions of rat brain. Journal of Comparative \& Physiological Psychology, 47, 419-427.

Rusiniak, K. W., Hankins, W. G., Garcia, J., \& Brett, L. P. (1979). Flavor-illness aversions: Potentiation of odor by taste in rats. $\mathrm{Be}$ havioral \& Neural Biology, 25, 1-17.

Simbayi, L. C., Bonkes, R. A., \& Burton, M. J. (1985). Acquired preferences for flavours mixed with nutritive and non-nutritive sweet solutions. Neuroscience Letters, 22(Suppl.), S158.

Simbayi, L. C., Bonkes, R. A., \& Burton, M. J. (1987). Can rats learn to associate a flavour with the delayed delivery of food? Appetite, 7, 41-53.

Smith, G. P., Jerome, C., Cushin, B. J., Eterno, R., \& Simansky, K. J. (1981). Abdominal vagotomy blocks the satiety effect of cholecystokinin in the rat. Science, 213, 1036-1037.

WalDBillig, R. J., \& BARTNESS, T. J. (1982). The suppression of sucrose intake by cholecystokinin is scaled according to the magnitude of the orosensory control over feeding. Physiology \& Behavior, 28, 591-595.

Waldbillig, R. J., O'Callaghan, M. (1980). Hormones and hedonics, cholecystokinin and taste: A possible behavioral mechanism of action. Physiology \& Behavior, 25, 25-30.

Young, P. T. (1948). Appetite, palatability and feeding habit: A critical review. Psychological Bulletin, 45, 289-320.

Zellner, D. A., Berridge, K. C., Grill, H. J., \& Ternes, J. W. (1985). Rats learn to like the taste of morphine. Behavioral Neuroscience, 99, 290-300.

(Manuscript received for publication February 12, 1988.) 